\title{
Dye aggregation and interaction of dyes with a water-soluble polymer in inkjet ink for textiles
}

\author{
Ju-Young Park, Yuichi Hirata and Kunihiro Hamada ${ }^{*}$ \\ Faculty of Textile Science and Technology, Shinshu University, 3-15-1 Tokida, Ueda, \\ Nagano 386-8567, Japan
}

\begin{abstract}
Detailed understanding of the interaction between dyes and additives and the aggregation behavior of the dye molecules in aqueous solutions is required to develop inkjet ink for textiles. In the present study, the aggregation behavior of three acid dyes (C. I. Acid Red 88, 13, and 27) containing different number of sulfonate groups in aqueous solutions was investigated by means of visible absorption spectroscopy. As a result, the higher the solubility of the dyes in water (the larger the number of sulfonate groups in the dyes), the lower are the aggregation constants of the dyes. For all the dyes, the aggregation constants decreased with increasing temperature, indicating the exothermic process of the dye aggregation. The thermodynamic process for C. I. Acid Red 88 having one sulfonate group is less enthalpic and more entropic than that for C. I. Acid Red 13 containing two sulfonate groups. C. I. Acid Red 27 including three sulfonate groups hardly form any aggregates. To elucidate the effects of the polymer additive, the binding constants of the dyes with the water-soluble polymer, poly(vinylpyrrolidone) (PVP), and the aggregation constants of the dyes in aqueous

\footnotetext{
* Corresponding author. Tel.: +8126821 5411; fax: +81268215391

E-mail address: khamada@shinshu-u.ac.jp (K. Hamada)
} 
polymer solutions were also estimated. The binding constants were also influenced by the number of the sulfonate groups in the acid dyes: the larger number of sulfonate groups diminished the binding constants. The aggregation constants in the presence of PVP were smaller than those in its absence at every temperature for all the dyes. This suggests that PVP has disaggregation effects. Furthermore, PVP makes the aggregation process less enthalpic with a greater entropic change. Thus, the aggregation process of the dyes in the polymer solutions is thermodynamically different from that in water, reflecting the interactions between the dyes and the polymer.

Keywords: inkjet ink; dye aggregation; acid dye; water-soluble polymer; visible absorption spectrum

\section{Introduction}

Recently, various inkjet ink for textiles has been developed, but more improvement of the ink is necessary. For example, the fixing ratio of dyes for textiles and the color fastness to washing, sweat, and light is found to be low, even though vivid color can be shown $[1,2]$.

The composition of the inkjet ink is very complicated due to the complex nature and very challenging requirements. The ink must have physicochemical properties which are specific to the various printing devices [3-7]. To formulate the inkjet ink, not only dyes or pigments but also additives are needed and the types and amounts of additives are the most important factors.

Commonly, the additives in the inkjet ink are used to adjust its physical properties such as stability, viscosity, surface tension, droplet form and so on [6-10]. Also 
various types of additives such as surfactants, inorganic salts and polymers have been used in the inkjet ink for textiles in order to solve the other problems which occur in printing processes. The additives affect the improvement of fastness properties, color strength, dye fixation and ink penetration. For example, the surfactants in the inkjet ink are used to absorb the colorants uniformly on the surface of the textile after the printing, improve the permeability of the ink, and realize more stable ejection of the ink [6,11-13]. Particularly, the nonionic surfactants are effective in improving level dyeing ability and in preventing feathering or bleeding [11-12]. To improve the binding force of the ink with the fiber, polymers are used as additives [14-16]. Water-soluble polymers affect the improvement of the water fastness and light fastness since the polymers can stabilize and immobilize the dyes both physically and chemically $[13,16-$ 18], though it causes negative effects on print quality [17]. The polymers offer not only rapid ink absorption but also high print density [15] and the durability of ink and prints is progressed by their addition into the inkjet ink $[6,19]$.

Various interactions such as dye-dye, dye-additive and additive-additive interactions are observed in the inkjet ink. The intermolecular interactions include electrostatic binding, $\pi-\pi$ interaction, hydrogen bonding, van der Waals force, and so on. The interdependence of dye structure and the type of additives has been shown to play a major role [20].

On the other hand, the aggregation behavior of dye molecules is investigated to grasp physical properties of dyes themselves in aqueous solutions. The dyes form aggregates through intermolecular force such as hydrogen bonding and van der Waals force. The forces of attraction responsible for such interactions are also capable of causing physical interactions between dye molecules to produce molecular species 
ranging in size from dimers to high-ordered aggregates containing many hundreds of molecules. In using aqueous dye solutions, the phenomenon of aggregation or selfassociation of dye molecules may be of advantage or disadvantage [21]. It is found that the dye aggregation makes light fastness to be better, i.e. the aggregation tendency of the dye has also proven to be important for light fastness [18,22-25] and image stability [23]. In the case of aqueous dye solutions containing polymers, the adsorption or binding processes often involve the aggregation. The cooperative binding of a dye with a polymer chain is a pertinent example [14,26]. Furthermore, an azo dye containing sulfonate groups shows good stability in contact with polymer [27] and the solubility of dyes are one of the most important factors for ink stability $[2,4]$.

In the present study, the effects of the additives used to formulate the inkjet ink for textiles were investigated. Especially, the aggregation behavior of three acid dyes (C. I. Acid Red 88, 13, and 27) containing sulfonate groups in the absence and presence of the additive were investigated by means of visible absorption measurements. To elucidate the effects of the polymer additive, the binding constants of the dyes with a water-soluble polymer, poly(vinylpyrrolidone) (PVP) and the aggregation constants in the presence of PVP were estimated. Furthermore, thermodynamic parameters were determined from the temperature dependence of the aggregation constants in the absence and presence of PVP. From the results, the effects of the polymer additives on the aggregation behavior are discussed.

\section{Experimental}

\section{Materials}

Three acid dyes containing the different number of sulfonate groups, C. I. Acid Red 
88 (R-1), C. I. Acid Red 13 (R-2), and C. I. Acid Red 27 (R-3) were used (Figure 1). R-1 was commercially purchased from Tokyo Chemical Industry Co., Ltd., and used after repeated salting-out with $\mathrm{NaCl}$ and reprecipitation of the aqueous dye solution with acetone. R-2 was prepared by the coupling reaction of diazotized 4-amino-1naphthalenesulfonic acid with sodium 2-hydroxy-6-naphthalenesulfonate under an alkaline condition and purified in the same manner as R-1. R-3 was purchased from Tokyo Chemical Industry Co., Ltd., and purified by repeated reprecipitation of the aqueous dye solution with acetone and recrystallization from $80 \%$ aqueous methanol. The purity and water content of the acid dyes were determined by elemental analysis (R-1: found: $\mathrm{C}, 59.25 ; \mathrm{H}, 3.54 ; \mathrm{N}, 6.96$; calcd. (containing $0.89 \% \mathrm{H}_{2} \mathrm{O}$ ): $\mathrm{C}, 59.47 ; \mathrm{H}$, 3.34; N, 6.93; R-2: found: $\mathrm{C}, 44.56 ; \mathrm{H}, 2.72 ; \mathrm{N}, 5.10$; calcd. (containing $6.3 \% \mathrm{H}_{2} \mathrm{O}$ ): $\mathrm{C}$, 44.80; H, 2.96; N, 5.22; R-3: found: C, 36.65; H, 2.58; N, 4.62; calcd. (containing $5.35 \%$ $\mathrm{H}_{2} \mathrm{O}$ ): C, 37.61; $\left.\mathrm{H}, 2.33 ; \mathrm{N}, 4.39\right)$. As an polymer additive, poly(vinylpyrrolidone) (PVP, Molecular weight 630,000) was purchased from Tokyo Chemical Industry Co., Ltd., and used without further purification (Figure 1). The number average molecular weight $(\mathrm{Mn})$, the weight average molecular weight $(\mathrm{Mw})$ and the polydispersity index (Mw/Mn) of PVP used in the present study are 148,000, 574,000 and 3.9, respectively, which were determined using gel permeation chromatography [28].

\section{Visible absorption spectrum measurements}

The visible absorption spectra of the aqueous dye solutions in the concentration range from $1 \times 10^{-5}$ to $1 \times 10^{-3} \mathrm{~mol} \mathrm{dm}^{-3}$ were measured by using a JASCO UV-530 spectrophotometer at $15,25,35$ and $45^{\circ} \mathrm{C}$ in the absence and presence of PVP with the concentration of $0.1 \mathrm{~mol} \mathrm{dm}^{-3}\left(11.11 \mathrm{~g} \mathrm{dm}^{-3}\right)$, where the PVP concentration is expressed 
based on monomer units. The spectra of aqueous solutions having various polymer concentrations and a constant dye concentration (R-1; $2.97 \times 10^{-5}$ mol dm ${ }^{-3}, \mathrm{R}-2 ; 2.81 \times$ $10^{-5} \mathrm{~mol} \mathrm{dm}{ }^{-3}, \mathrm{R}-3 ; 2.83 \times 10^{-5} \mathrm{~mol} \mathrm{dm}^{-3}$ ) were measured in order to determine the binding constants of the dyes with the polymer.

(Figure 1)

\section{Results and Discussion}

\section{Aggregation of dyes in aqueous solutions}

The visible absorption spectra of the three acid dyes (R-1, R-2, and R-3) with the concentration of $1 \times 10^{-5} \mathrm{~mol} \mathrm{dm}^{-3}$ are shown in Figure 2. Their maximum absorption wavelengths were 507, 508, and $520 \mathrm{~nm}$, respectively, indicating that the number of sulfonate groups in the dyes molecular cause a red shift. And the extinction coefficients, $\varepsilon$, at the maximum absorption wavelengths increased in the order of R-1< $\mathrm{R}-2<\mathrm{R}-3$, which is comparable to the order of the number of sulfonate groups.

(Figure 2)

Figure 3 shows the visible absorption spectra of aqueous R-1 solutions with various concentrations. The maximum absorption wavelength for the aqueous R-1 solutions, shifted to lower wavelength (blue shift) and the extinction coefficient at that wavelength decreased with increasing dye concentration, indicating that the dye forms aggregates in aqueous solutions with higher concentration. Such a blue shift suggests that the dyes form H-aggregates $[29,30]$. To analyze the spectral change with dye concentration, it is convenient to use the extinction coefficients, $\varepsilon$, at the wavelength where the largest difference was observed in order to obtain the most accurate values, although the same values were given at all the wavelengths measured because of the existence of isosbestic 
points, as described in the previous paper [31]. Here, $526 \mathrm{~nm}$ were used as the wavelength where the largest difference was observed for all the dyes.

As can be found in Figure 3, the spectral change with dye concentration was accompanied by the appearance of isosbestic point for R-1. The similar spectral change was also observed for R-2 and R-3. The isosbestic points for R-1, R-2, and R3 were observed at 572, 568, and $579 \mathrm{~nm}$, respectively. This fact indicates that a single equilibrium exists in the concentration range under examination. The existence of an isosbestic point is a good indicator of a true equilibrium process [32].

(Figure 3)

The aggregation number, $n$, of the dyes was determined by the procedure described in a previous paper [33], resulting in $n=2$ for all the dyes. Therefore, for all the dye solutions, the following equilibrium between the dye monomer, D, and the dye dimer, $\mathrm{D}_{2}$, can be assumed:

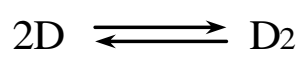

From this equilibrium, the aggregation constant, $K_{\text {agg }}$, is expressed as follows:

$$
K_{\mathrm{agg}}=\frac{C_{\mathrm{D} 2}}{C_{\mathrm{D}}{ }^{2}}
$$

where $C_{\mathrm{D}}$ and $C_{\mathrm{D} 2}$ are the concentrations of the dye monomer and dimer, respectively. If the molar extinction coefficient observed at a certain wavelength is designated $\varepsilon$ and the molar extinction coefficients of dye monomer and dimer are $\varepsilon_{\mathrm{D}}$ and $\varepsilon_{\mathrm{D} 2}$, respectively, the following equation is derived:

$$
\varepsilon=\varepsilon_{\mathrm{D}} \frac{C_{\mathrm{D}}}{C_{0}}+\varepsilon_{\mathrm{D} 2} \frac{2 C_{\mathrm{D} 2}}{C_{0}}
$$

where $C_{0}$ is the total dye concentration. Considering $C_{0}=C_{\mathrm{D}}+2 C_{\mathrm{D} 2}$, from eqn (3), $C_{\mathrm{D}}$ and $C_{\mathrm{D} 2}$ can be written as follows. 


$$
\begin{gathered}
C_{\mathrm{D}}=\frac{\varepsilon_{\mathrm{D} 2}-\varepsilon}{\varepsilon_{\mathrm{D} 2}-\varepsilon_{\mathrm{D}}} C_{0} \\
C_{\mathrm{D} 2}=\frac{\varepsilon_{\mathrm{D} 2}-\varepsilon}{\varepsilon_{\mathrm{D} 2}-\varepsilon_{\mathrm{D}}} \cdot \frac{C_{0}}{2}
\end{gathered}
$$

Substituting eqn (4) and (5) into eqn (2), the equation for $\varepsilon$ is derived: [31,34]

$$
\varepsilon=\frac{-1+\left(1+8 K_{\mathrm{agg}} C_{0}\right)^{1 / 2}}{4 K_{\mathrm{agg}} C_{0}} \varepsilon_{\mathrm{D}}+\frac{4 K_{\mathrm{agg}} C_{0}+1-\left(1+8 K_{\mathrm{agg}} C_{0}\right)^{1 / 2}}{4 K_{\mathrm{agg}} C_{0}} \varepsilon_{\mathrm{D} 2}
$$

So we can determine the $K_{\mathrm{agg}}, \varepsilon_{\mathrm{D}}$, and $\varepsilon_{\mathrm{D} 2}$ values using nonlinear least-squares method (SigmaPlot, SPSS Inc.). The extinction coefficients calculated from the $K_{\text {agg }}, \varepsilon_{\mathrm{D}}$, and $\varepsilon_{\mathrm{D} 2}$ values are expressed by the solid lines in Figure 4, showing good agreement with the observed ones for all the dyes.

\section{(Figure 4)}

The aggregation constants, $K_{\text {agg, }}$, thus obtained are given in Table 1 . The $K_{\text {agg }}$ values determined in the present study were a little bit smaller than those reported in a previous paper [31], but showed similar tendencies. The $K_{\text {agg }}$ values decreased with an increase in the number of sulfonate groups in the acid dyes at all temperatures. It is worthwhile to mention that the introduction of sulfonate groups into the dye molecules increases the water solubility in the order of R-1 $<\mathrm{R}-2<\mathrm{R}-3$. The order corresponds to the decreasing order of $K_{\mathrm{agg}}(\mathrm{R}-1>\mathrm{R}-2>\mathrm{R}-3)$, and the same tendency was shown in the previous papers $[21,31,35]$. For all the dyes, the $K_{\text {agg }}$ values decreased with increasing temperature, indicating the exothermic process of the dye aggregation.

To discuss the aggregation process in more detail, the thermodynamic parameters, the enthalpy change, $\Delta H_{\text {agg }}$, and the entropy change, $\Delta S_{\text {agg, }}$ were determined from the temperature dependence of $K_{\mathrm{agg}}$ (Table 1$)$. The $K_{\mathrm{agg}}$ values for R-3 were estimated as 0 
$\sim 3 \mathrm{dm}^{3} \mathrm{~mol}^{-1}$, indicating that it is difficult for R-3 to form a dimer in the concentration region measured.

So it is very difficult to calculate the thermodynamic parameters, as described in the previous paper $[33,36]$. The thermodynamic behavior for $\mathrm{R}-1$ is less enthalpic and more entropic than that for R-2. The ability of dyes to associate with themselves is responsible for electrostatic repulsion, hydrophobic bonding, $\pi-\pi$ stacking, hydrophobic interaction, and so on. The electrostatic repulsion between R-1 molecules is believed to be smaller than that for R-2, because R-1 and R-2 have one and two sulfonate groups respectively. Furthermore, as R-1 is more hydrophobic than R-2, hydrophobic interaction affects R-1 rather than R-2 in the aqueous dye solutions. The thermodynamic parameters reflect the situation of the interactions.

From the aggregation constants and the extinction coefficients obtained above, considering $C_{0}=C_{\mathrm{D}}+2 C_{\mathrm{D} 2}$ and eqn (2), the ratio of the dye monomers and dimers can be calculated (Figure 5). The percentage of dye dimers for R-1 was larger than those for R-2 in all the dye concentration regions.

\section{(Figure 5)}

The extinction coefficients of the monomer, $\varepsilon_{\mathrm{D}}$, determined are given in Table 2 together with the extinction coefficients of the dimer, $\varepsilon_{\mathrm{D} 2}$. From this table, the $\varepsilon_{\mathrm{D}}$ values for R-1 and R-2 in water were similar, but the $\varepsilon_{\mathrm{D} 2}$ values for R-1 was smaller than that for R-2, suggesting that the dimer structure was different between R-1 and R-2. On the other hand, for R-3, the extinction coefficients of the monomer, $\varepsilon_{\mathrm{D}}$, are appreciably lager than those for the other dyes. It may be noted that the different results of the $\varepsilon_{\mathrm{D}}$ and $\varepsilon_{\mathrm{D} 2}$ values of the three dyes (the aggregation behavior of the dyes) are reflected by the spectra shown in Figure 2. 
(Table 2)

\section{Interaction between dyes and PVP}

The effect of successive addition of PVP on the absorption spectra of aqueous R-1 solutions is represented in Figure 6, where the polymer concentration is expressed based on monomer units. Isosbestic points were defined in the polymer concentration region examined. This fact makes it possible to assume a single equilibrium in the R-1/PVP systems. The similar spectral changes were also observed for the other dyes.

(Figure 6)

To analyze the spectral change with PVP concentration, the extinction coefficients, $\varepsilon$, at the wavelength where the largest difference was observed are useful. These extinction coefficients decreased with increasing polymer concentration for all the dyes, as shown in Figure 7. The binding constants, $K_{\text {bind, }}$ are calculated from the change of the extinction coefficients.

(Figure 7)

We assume that the following single equilibrium exists in the dye/PVP systems because the isosbestic points were observed.

$$
\mathrm{D}+\mathrm{P} \rightleftarrows \mathrm{D} \cdot \mathrm{P}
$$

where D, P and D - P express the dye, PVP and dye/PVP complex, respectively. When the concentrations of total dye, total PVP, bound dye and free dye are defined as $C_{0}, C_{\mathrm{P}}, C_{\mathrm{b}}$, and $C_{\mathrm{f}}$, respectively, the binding constant of the dye with PVP ( $\left.K_{\text {bind }}\right)$ should be expressed by eqn (8):

$$
K_{\text {bind }}=\frac{C_{\mathrm{b}}}{\left(C_{\mathrm{P}}-C_{\mathrm{b}}\right) \cdot C_{\mathrm{f}}}
$$

Since $C_{0}=C_{\mathrm{f}}+C_{\mathrm{b}}$, eqn (8) can be rewritten by eqn (9): 


$$
C_{\mathrm{b}}=\frac{1}{2}\left\{\mathrm{~A}-\left(\mathrm{A}^{2}-4 C_{0} C_{\mathrm{P}}\right)^{1 / 2}\right\}
$$

where $\mathrm{A}=C_{0}+C_{\mathrm{p}}+1 / K_{\text {bind. }}$. On the other hand, if $\varepsilon_{\mathrm{f}}$ and $\varepsilon_{\mathrm{b}}$ are the extinction coefficients of the free and bound dye, respectively, then the observed extinction coefficient, $\varepsilon$, can be expressed as follows:

$$
\varepsilon=\frac{C_{\mathrm{f}}}{C_{0}} \cdot \varepsilon_{\mathrm{f}}+\frac{C_{\mathrm{b}}}{C_{0}} \cdot \varepsilon_{\mathrm{b}}
$$

By substituting eqn (9) and $C_{\mathrm{f}}=C_{0}-C_{\mathrm{b}}$ into eqn (10), we can obtain.

$$
\varepsilon=\varepsilon_{\mathrm{f}}+\frac{\varepsilon_{\mathrm{b}}-\varepsilon_{\mathrm{f}}}{2 C_{0}}\left\{\mathrm{~A}-\left(\mathrm{A}^{2}-4 C_{0} \cdot C_{\mathrm{P}}\right)^{1 / 2}\right\}
$$

On the basis of eqn (11), the binding constant, $K_{\text {bind }}$, and the extinction coefficient of the bound dye, $\varepsilon_{b}$, were calculated by using the nonlinear least-squares method (SigmaPlot, SPSS Inc.) [37-41]. The binding constants, $K_{\text {bind, }}$, thus calculated are given in Table 3. The binding constants of the acid dyes with PVP were dependent on the dye structure: the $K_{\text {bind }}$ values decreased with an increase in the number of sulfonate groups in the acid dyes at all temperatures. It is worthwhile to mention that the introduction of sulfonate groups into the dye molecule increases the water solubility, i.e. the solubility increases in the order of R-1 $<\mathrm{R}-2<\mathrm{R}-3$, which corresponds to the decreasing order of $K_{\text {bind }}(\mathrm{R}-1>\mathrm{R}-2>\mathrm{R}-3)$. This suggests that the affinity to PVP decreases with increasing water solubility.

For further discussion, the thermodynamic parameters for the binding, viz. the enthalpy change, $\Delta H_{\text {bind, }}$ and the entropy change, $\Delta S_{\text {bind }}$, were determined from the temperature dependence of $K_{\text {bind }}$ (Table 3). The $\Delta H_{\text {bind }}$ values for all the dyes were negative, showing that the binding processes are exothermic. The $\Delta H_{\text {bind }}$ and $\Delta S_{\text {bind }}$ values did not show a tendency with increasing number of sulfonate groups. This 
might be due to the complicity in dehydration of water molecules around the dyes and PVP. From the above results, it is concluded that the dye structures, especially the number of sulfonate groups, influences the binding behavior of the acid dyes with PVP.

\section{(Table 3)}

\section{Aggregation of dyes in the polymer solutions}

The absorption spectra of aqueous R-1 solutions in the absence and presence of PVP are shown in Figure 8. Isosbestic points were defined in the dye concentration region examined for each system in the absence and presence of PVP. Such spectral changes were also observed for all the other dyes. The existence of the isosbestic points makes it possible to assume a single equilibrium in the aggregation processes even in the presence of PVP. The addition of PVP decreased the degree of the spectral change with increasing dye concentration, for R-1: by the addition of PVP, the maximum absorption wavelengths of the dyes were shifted to lower wavelength (blue shift) and the extinction coefficients at those wavelengths were reduced. Although the similar spectral change was observed for R-2, the change for R-3 was very small.

(Figure 8)

Figure 9 shows the dependence of $\varepsilon$ at $526 \mathrm{~nm}$, at which the change of the extinction coefficients was the largest, on dye concentration in the absence and presence of PVP for all the dyes. The addition of PVP decreased the degree of the change in $\varepsilon$ with increasing dye concentration, for R-1 and R-2. In the case of the R-3, the extinction coefficients, $\varepsilon$, hardly changed both in the absence and presence of PVP.

(Figure 9)

As described in a previous paper [36], the following four equilibria exist in the dye/PVP solutions can be assumed. 


$$
\begin{aligned}
& K_{\text {agg }} \\
& 2 \mathrm{D}+\mathrm{P} \quad \rightleftarrows \quad \mathrm{D}_{2}+\mathrm{P} \\
& \uparrow K_{\text {bind }} \quad K_{\text {bind }} \operatorname{Dim} \uparrow \\
& \text { 2D.P } \rightleftarrows \quad \mathrm{D}_{2} \cdot \mathrm{P} \\
& K_{\text {agg }} \text { PVP }
\end{aligned}
$$

where $\mathrm{D} \cdot \mathrm{P}$ and $\mathrm{D}_{2} \cdot \mathrm{P}$ represent the dye monomer/PVP and the dye dimer/PVP complexes respectively. $\quad K_{\text {agg }}{ }^{\mathrm{PVP}}$ and $K_{\text {bind }}{ }^{\mathrm{Dim}}$ are the aggregation constant of the dye on the PVP chain and the binding constant of the dye dimer with PVP, respectively. The component concentration can be expressed by the following mass balance equation:

$$
C_{0}=C_{\mathrm{D}}+2 C_{\mathrm{D} 2}+C_{\mathrm{bD}}+2 C_{\mathrm{bD} 2}
$$

where $C_{\mathrm{bD}}$ and $C_{\mathrm{bD} 2}$ are the concentration of the dye bound monomer and dimer, respectively. From the equilibria shown in eqn (12), the aggregation constant of the dye on PVP is expressed as follows:

$$
K_{\mathrm{agg}}^{\mathrm{PVP}}=\frac{C_{\mathrm{bD} 2}}{C_{\mathrm{bD}}{ }^{2}}
$$

If the molar extinction coefficient observed at a certain wavelength is designated $\varepsilon$ and $\varepsilon_{\mathrm{bD}}$ and $\varepsilon_{\mathrm{bD} 2}$ are the molar extinction coefficients of bound monomer and dimer, respectively, the following equation is derived:

$$
\varepsilon=\varepsilon_{\mathrm{D}} \frac{C_{\mathrm{D}}}{C_{0}}+\varepsilon_{\mathrm{D} 2} \frac{2 C_{\mathrm{D} 2}}{C_{0}}+\varepsilon_{\mathrm{bD}} \frac{C_{\mathrm{bD}}}{C_{0}}+\varepsilon_{\mathrm{bD} 2} \frac{2 C_{\mathrm{bD} 2}}{C_{0}}
$$

As $C_{\mathrm{p}}\left(0.1 \mathrm{~mol} \mathrm{dm}^{-3}\right)$ is much larger than $C_{0}\left(10^{-5} \sim 10^{-3} \mathrm{~mol} \mathrm{dm}^{-3}\right), C_{\mathrm{p}}-C_{\mathrm{b}}$ can be approximated by $C_{\mathrm{p}}$. As a result, eqn (8) can be rewritten as eqn (16): 


$$
C_{\mathrm{f}}=\frac{C_{\mathrm{b}}}{K_{\mathrm{bind}} \cdot C_{\mathrm{P}}}
$$

When $K_{\text {bind }}$ is $125 \sim 780, C_{\mathrm{f}} / C_{\mathrm{b}}$ becomes $0.08 \sim 0.013$, indicating that the free dye concentration, $C_{\mathrm{f}}\left(=C_{\mathrm{D}}+C_{\mathrm{D} 2}\right)$, is very small (less than $8 \times 10^{-5} \mathrm{~mol} \mathrm{dm}^{-3}$ ). So $C_{\mathrm{D} 2}$ is negligible. From the above assumption, eqn (15) can be rewritten as follows:

$$
\varepsilon=\varepsilon_{\mathrm{bD}} \frac{C_{\mathrm{bD}}}{C_{0}}+\varepsilon_{\mathrm{bD} 2} \frac{2 C_{\mathrm{bD} 2}}{C_{0}}
$$

So a similar equation to eqn (6) can be derived:

$$
\varepsilon=\frac{-1+\left(1+8 K_{\mathrm{agg}}{ }^{\mathrm{PVP}} C_{0}\right)^{1 / 2}}{4 K_{\mathrm{agg}}^{\mathrm{PVP}} C_{0}} \varepsilon_{\mathrm{bD}}+\frac{4 K_{\mathrm{agg}}{ }^{\mathrm{PVP}} C_{0}+1-\left(1+8 K_{\mathrm{agg}}{ }^{\mathrm{PVP}} C_{0}\right)^{1 / 2}}{4 K_{\mathrm{agg}}{ }^{\mathrm{PVP}} C_{0}} \varepsilon_{\mathrm{bD} 2}
$$

The aggregation constants of the dyes in the PVP solutions, $K_{\text {agg }}{ }^{\text {PVP }}$, and the molar extinction coefficients of bound monomer and dimer, $\varepsilon_{\mathrm{bD}}$ and $\varepsilon_{\mathrm{bD} 2}$, were determined on the basis of eqn (18) by using the nonlinear least-squares equation (SigmaPlot, SPSS Inc.). The calculated extinction coefficients are expressed by the solid line in Figure 9, showing good agreement with the observed ones for all the three dyes. However, in the case of R-3, the aggregation constants could not be calculated with a high degree of accuracy, because they were very small.

Table 4 shows the aggregation constants, $K_{\mathrm{agg}}^{\mathrm{PVP}}$, for R-1 and R-2 in the presence of PVP. The aggregation constants in the presence of PVP were smaller than those in its absence at every temperature for both the dyes. This suggests that PVP has disaggregation effects. The reason that the polymer favours disaggregation might be explained as follows; the majority of dye becomes bound to PVP under the conditions employed and since the monomeric form is dominant over the dimeric form when bound to the polymer, the overall effect is that disaggregation is favoured over 
aggregation. The aggregation constants for R-1 were greater than those for R-2 in the absence and presence of the PVP. The effects of the sulfonate groups are observed not only in aqueous solutions but also on the polymer chains.

Furthermore, the $\Delta H_{\text {agg }}{ }^{\mathrm{PVP}}$ and $\Delta S_{\text {agg }}^{\mathrm{PVP}}$ values calculated from the temperature dependence of $K_{\mathrm{agg}}$ PVP indicate that PVP makes the aggregation process less enthalpic and more entropic. This result might be explained as follows. The positively charged pyrrolidone rings of PVP can interact electrostatically with the anionic groups of the acid dyes, by which the structures of the dye aggregates are different between the absence and presence of PVP. This fact is reflected by the thermodynamic parameters.

(Table 4)

The determined extinction coefficients of the dye monomer and dimer in the presence of PVP, $\varepsilon_{\mathrm{bD}}$ and $\varepsilon_{\mathrm{bD} 2}$ are given in Table 5. From this table, it is apparent that the $\varepsilon_{\mathrm{bD}}$ and $\varepsilon_{\mathrm{bD} 2}$ values change with temperature and the existence of the PVP at $526 \mathrm{~nm}$. The $\varepsilon_{\mathrm{bD}}$ values and the $\varepsilon_{\mathrm{bD} 2}$ values were quite different from those in the absence of PVP, $\varepsilon_{\mathrm{D}}$ and $\varepsilon_{\mathrm{D} 2}$ (Table 2), indicating that the polymer chains affect the extinction coefficients. The difference of the dimer structure between the absence and presence of PVP also affects the $\varepsilon$ values, as described in a previous paper [36].

(Table 5)

\section{Conclusions}

As a result for the aggregation behavior of the dye molecules in aqueous solutions, the higher the solubility of the dyes in water (the larger the number of sulfonate groups in the dyes), the lower are the aggregation constants of the dyes. This suggests that the hydrating water molecules around the dyes play an important role in the aggregation process. For all the dyes, the $K_{\text {agg }}$ values decreased with increasing temperature, 
indicating the exothermic process of the dye aggregation. The thermodynamic behavior for R-1 is less enthalpic and more entropic than that for R-2, i.e., the hydrophobic interaction is strongly concerned with the aggregation process.

The aggregation constants in the presence of PVP were smaller than those in its absence at every temperature for the all dyes. This suggests that PVP has disaggregation effects. PVP makes the aggregation process less enthalpic with a greater entropic change. From the above results, it is concluded that the aggregation process of the dyes in the polymer solutions is thermodynamically different from that in water, reflecting the interactions between the dyes and the polymer chains.

Thus, the elucidation of the aggregation behavior of dye molecules in the absence and presence of the additive in inkjet ink makes it possible to discuss their effects on the physical properties of ink such as viscosity, surface tension, droplet form and so on for adequate preparation of inkjet ink.

\section{Acknowledgements}

This work was supported by Grant-in-Aid for Global COE Program by the Ministry of Education, Culture, Sports, Science and Technology, JAPAN.

\section{References}

[1] H Anzai, J. Jpn. Soc. Colour. Mater., 81(1) (2008) 23.

[2] M K Ali, NIP 24th International Conference on Digital Printing Technologies and Digital Fabrication, Pittsburgh, USA, (2008) 542.

[3] S Magdassi, The chemistry of inkjet inks, Ed S Magdassi (UK: World Scientific Publishing, 2008) 19. 
[4] S J Moon, Dyeing and Finishing, 1 (2006) 48.

[5] W C Tincher, Q Hu, X Li, T Tian and J Zeng, NIP 14th International Conference on Digital Printing Technologies, Toronto, Canada (1998) 243.

[6] C Schmid, The chemistry of inkjet inks, Ed S Magdassi (UK: World Scientific Publishing, 2008) 123.

[7] D J Tyler, Textile Progress, 37(4), (2005) 24.

[8] J S Bae and Y A Son, Journal of the Research Institute of Industrial Technology, 21(1) (2006) 33.

[9] H Morimoto, K Kudo, A Tomotake and Y Kawashima, NIP 22nd International Conference on Digital Printing Technologies, Denver, USA (2006) 619.

[10] H D Le, Journal of Imaging Science and Technology, 42(1) (1998) 49.

[11] P Gregory, Optics \& Laser Technology, 38 (2006) 306.

[12] M Taniguchi, US6447592B1 (Seiko Epson Co.; 2002).

[13] D Alfekri, G Staley, B Chin, B Hardin and C Siswanto, US6001137 (Encad, Inc.; 1999).

[14] J Wang, T Chen, O Glass and S J Sargeant, NIP 15th International Conference on Digital Printing Technologies, Orlando, USA (1999) 183.

[15] J Pinto and M Nicholas, NIP 13rd International Conference on Digital Printing Technologies, Seattle, USA (1997) 420.

[16] S Yuan, S Sargeant, J Rundus, N Jones and K Nguyen, NIP 13rd International Conference on Digital Printing Technologies, Seattle, USA (1997) 413.

[17] K Khoultchaev and T Graczyk, Journal of Imaging Science and Technology, 45(1) (2001) 16. 
[18] A A Clifton and N Nugent, NIP 16th International Conference on Digital Printing Technologies, Vancouver, Canada (2000) 762.

[19] J C Hornby, K H Kung, J S Locke and J W Wheeler, US0032098 Al (E. I. du pont de Nemours and company legal patent records center; 2008).

[20] M Fryberg and R Hofmann, NIP 16th International Conference on Digital Printing Technologies, Vancouver, Canada (2000) 95.

[21] B C Burdett, Aggregation Processes in Solution. Eds E Wyn-Jones and J Gormally (Amsterdam: Elsevier, 1983) 241.

[22] M Fryberg, Rev. Prog. Coloration, 35 (2005) 1.

[23] R Steiger and P A Brugger, NIP 14th International Conference on Digital Printing Technologies, Toronto, Canada (1998) 114.

[24] P Doll, F Shi, S Kelly and W Wnek, NIP 14th International Conference on Digital Printing Technologies, Toronto, Canada; (1998) 118.

[25] C H Giles, G Baxter, W A Black, N Macaulay and S M K Rahman, Textile Research Journal, 30 (1960) 934.

[26] S Pak, Y Ando, J Koshikawa and T iijima, Journal of Macromolecular Science, Part B: Physics, 23(1) (1984) 85.

[27] A Naisby, J Suhadolnik, A Debellis, D Pennant and W Renz, NIP 18th International Conference on Digital Printing Technologies, San Diego, USA (2002) 749.

[28] H Hirai and N Yakura, Protecting polymers in suspension of metal nanoparticles, Polymers for Advanced Technologies, 12, (2001) 724.

[29] A H Herz, Photogr. Sci. Eng., 18(3) (1974) 323.

[30] A H Herz, Advanced Colloid Interface Science, 8 (1977) 237. 
[31] K Hamada and M Mitsuishi, Dyes Pigm., 19 (1992) 161.

[32] A Cooper, Biophysical Chemistry, Ed A Cooper (UK: Royal Society of Chemistry, 2004) 27.

[33] K Hamada, H Nonogaki, Y Fukushima, B Munkhbat and M Mitsuishi, Dyes Pigm., 16 (1991) 111.

[34] K Hamada, M Mitshishi, M Ohira and K Miyazaki. The Journal of Physical Chemistry, 97 (1993) 4926.

[35] D G Duff, D J Kirkwood and D M Stevenson, Journal of the Society of Dyers and Colourists, 93 (1977) 303.

[36] K Hamada, M Fujita and M Mitsuishi, Journal of the Chemical Society Faraday Transactions, 86(24) (1990) 4031.

[37] K Hamada and E Miyawaki, Dyes Pigm., 38 (1998) 147.

[38] J Qian, K Hamada and M Mitsuishi, Dyes Pigm., 25 (1994) 167.

[39] J Qian, K Hamada and M Mitsuishi, Dyes Pigm., 26 (1994) 217.

[40] K Hamada, J Qian, Y Hirata, K Satomura and M Mitsuishi, Dyes Pigm., 31 (1996)

19.

[41] K Hamada, K Satomura and M Mitsuishi, Dyes Pigm., 31 (1996) 205. 


\section{SEQUENCE OF FIGURES THAT APPEARED IN THE MANUSCRIPT}

Figure 1 Chemical structure of acid dyes and PVP used

Figure 2 Visible absorption spectra of aqueous dye solutions at $25{ }^{\circ} \mathrm{C}$ (Dye concentration: $1 \times 10^{-5} \mathrm{~mol} \mathrm{dm}^{-3}$ )

Figure 3 Visible absorption spectra of aqueous R-1 solutions at $25^{\circ} \mathrm{C}$

Figure 4 Dependence of $\varepsilon$ on the dye concentration at $25^{\circ} \mathrm{C}$ and $526 \mathrm{~nm}$ : The solid lines show the calculated extinction coefficients

Figure 5 The ratio of dye dimers and monomers in the aqueous dye solutions $25^{\circ} \mathrm{C}$

Figure 6 Visible absorption spectra of aqueous R-1 solutions in the absence and presence of PVP at $25^{\circ} \mathrm{C}$

Figure 7 Dependence of $\varepsilon$ on PVP concentration at $25{ }^{\circ} \mathrm{C}$ (R-1, $492 \mathrm{~nm}$; R-2, $494 \mathrm{~nm}$; $\mathrm{R}-3,509 \mathrm{~nm}$ ) The solid lines show the calculated extinction coefficients

Figure 8 Visible absorption spectra of R-1 aqueous solutions in the absence and presence of PVP $\left(0.1 \mathrm{~mol} \mathrm{dm}^{-3}\right)$ at $25^{\circ} \mathrm{C}$

Figure 9 Dependence of $\varepsilon$ on the dye concentration in the absence and presence of PVP $\left(0.1 \mathrm{~mol} \mathrm{dm}^{-3}\right)$ at $25{ }^{\circ} \mathrm{C}$ and $526 \mathrm{~nm}$ : The solid lines show the calculated extinction coefficients 


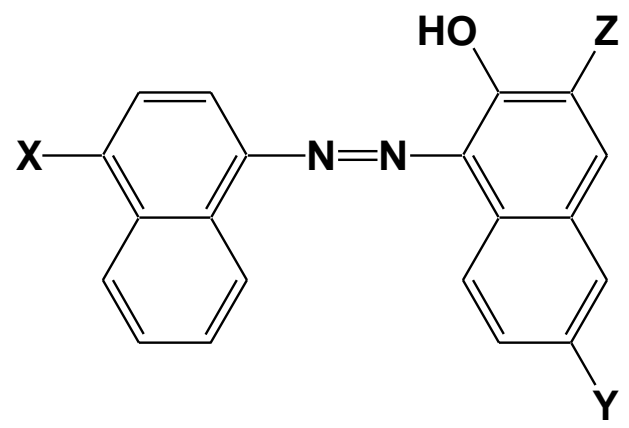

R-1: $X=\mathrm{SO}_{3} \mathrm{Na}, \quad Y=\mathrm{H}, \quad Z=\mathrm{H}$

R-2: $X=\mathrm{SO}_{3} \mathrm{Na}, \quad Y=\mathrm{SO}_{3} \mathrm{Na}, \quad Z=\mathrm{H}$

R-3: $X=\mathrm{SO}_{3} \mathrm{Na}, \quad Y=\mathrm{SO}_{3} \mathrm{Na}, \quad Z=\mathrm{SO}_{3} \mathrm{Na}$

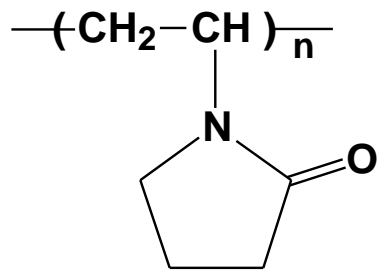

PVP

Figure 1 Chemical structure of acid dyes and PVP used 


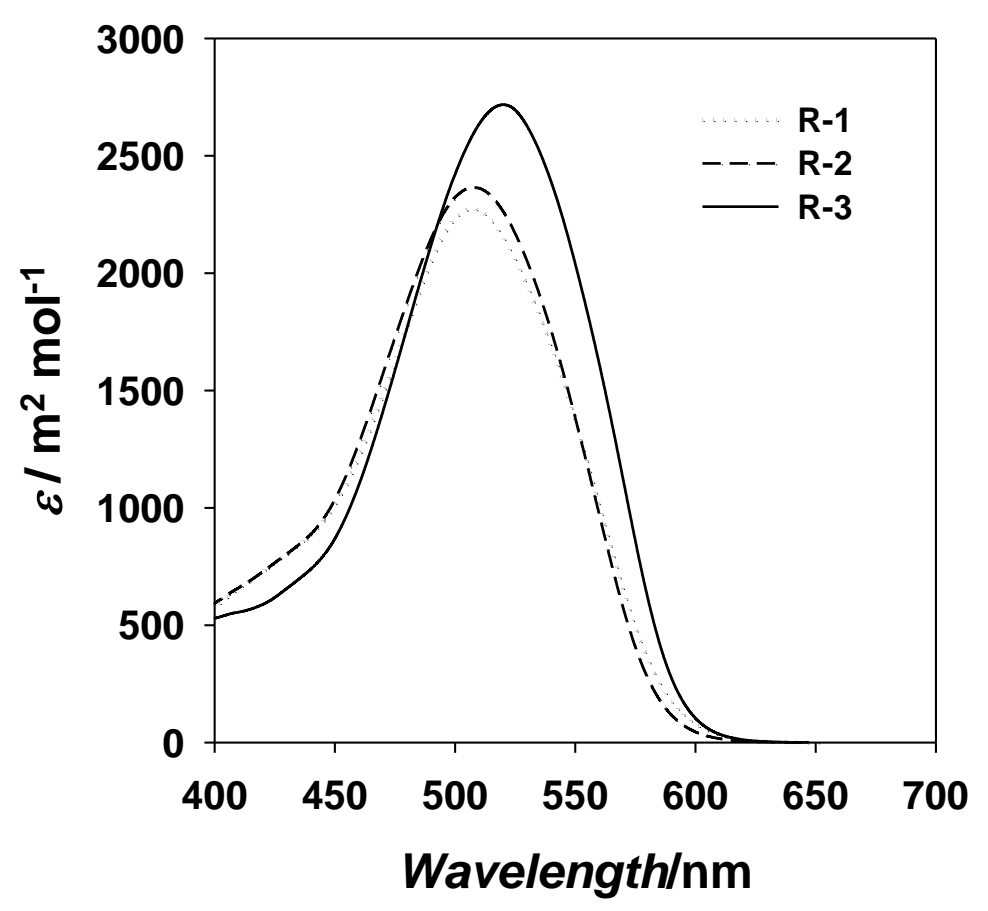

Figure 2 Visible absorption spectra of aqueous dye solutions at $25^{\circ} \mathrm{C}$ (Dye concentration : $1 \times 10^{-5} \mathrm{~mol} \mathrm{dm}^{-3}$ ) 


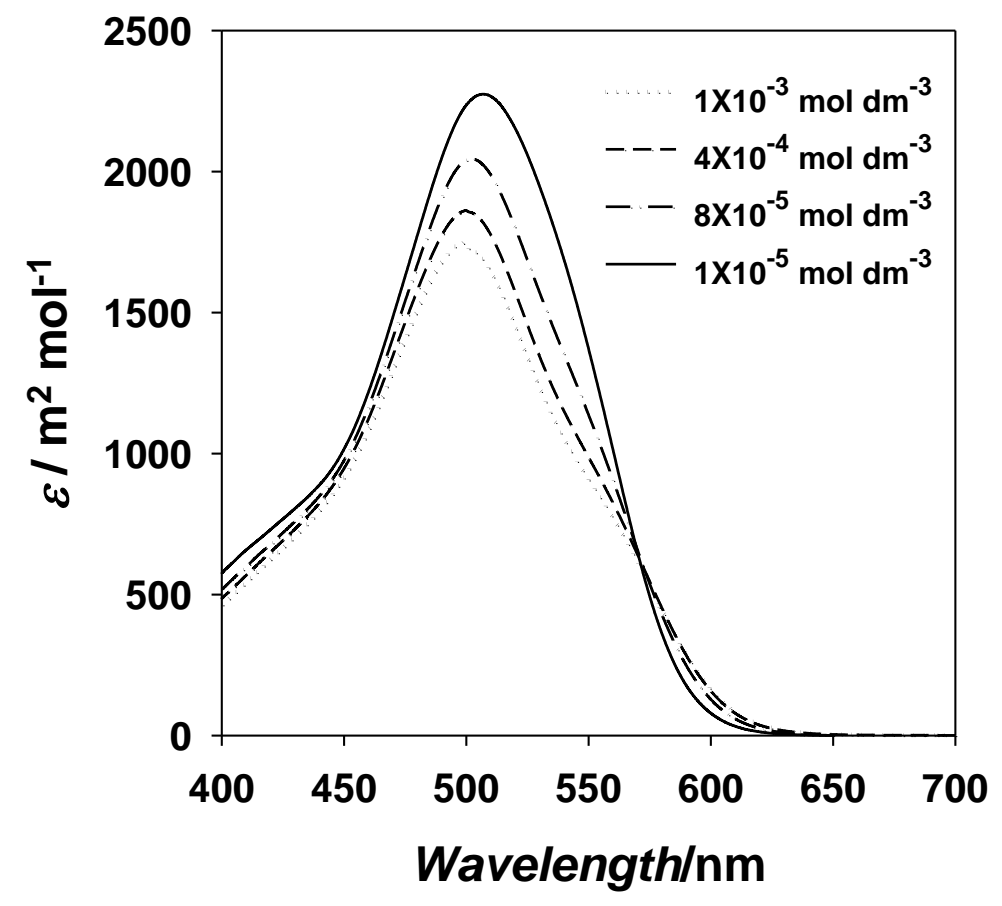

Figure 3 Visible absorption spectra of aqueous R-1 solutions at $25^{\circ} \mathrm{C}$ 


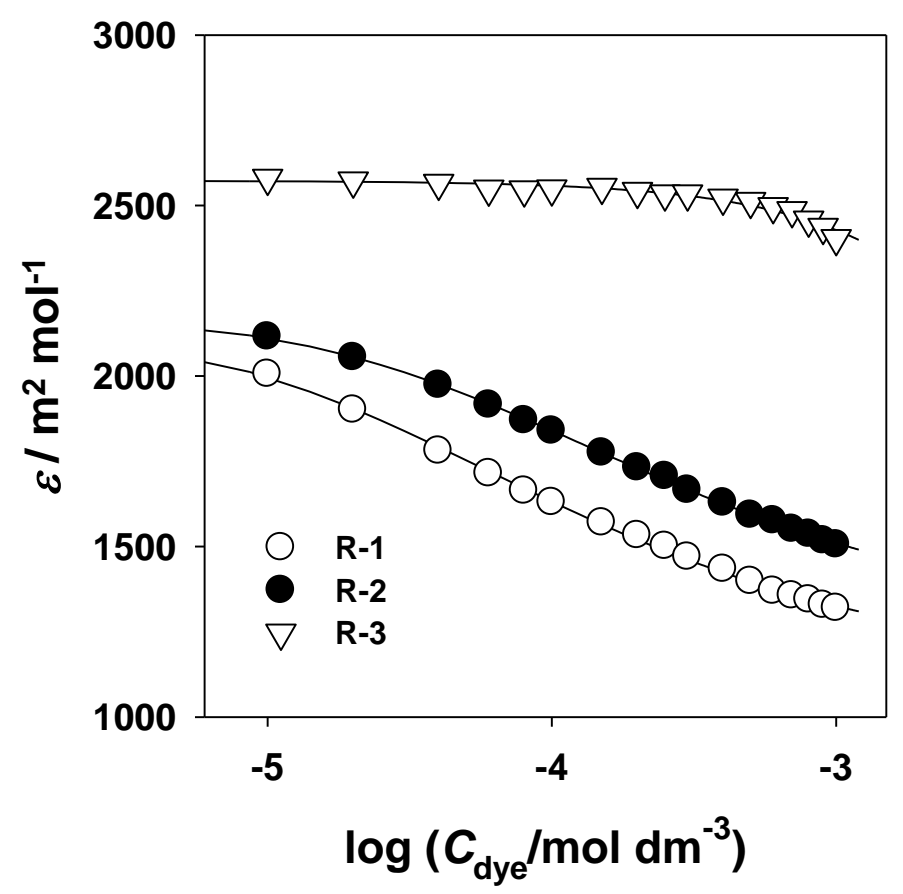

Figure 4 Dependence of $\varepsilon$ on the dye concentration at $25^{\circ} \mathrm{C}$ and $526 \mathrm{~nm}$ : The solid lines show the calculated extinction coefficients 

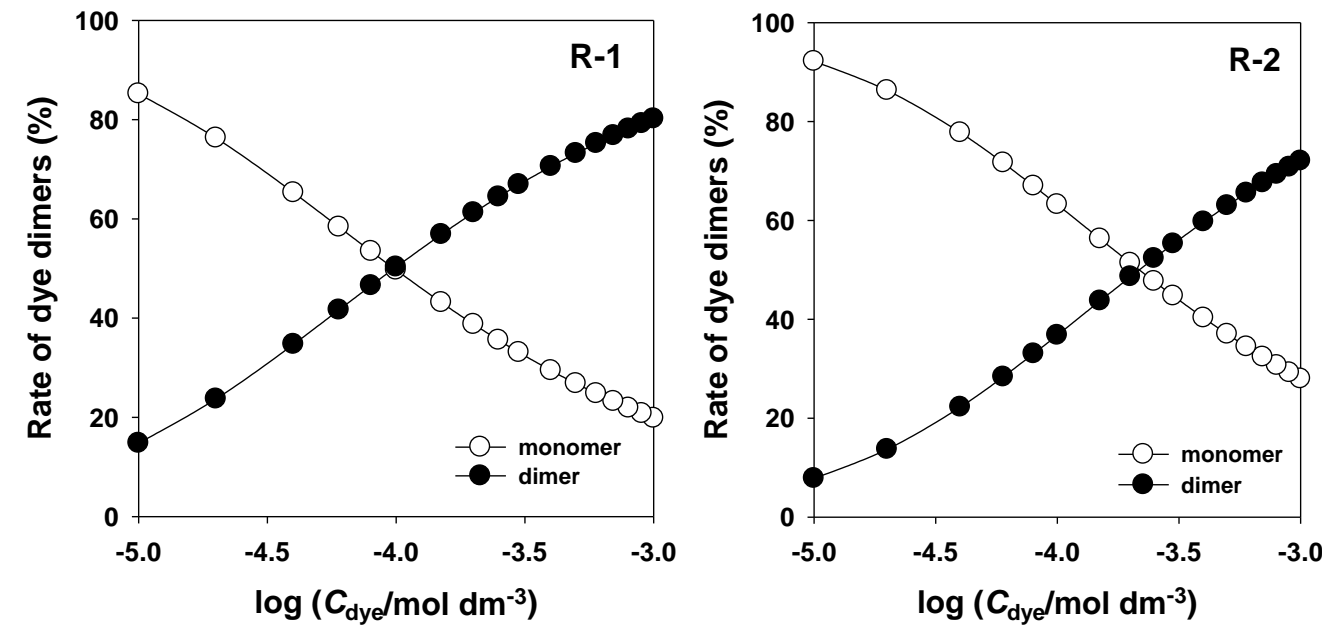

Figure 5 The ratio of dye dimers and monomers in the aqueous dye solutions $25^{\circ} \mathrm{C}$ 


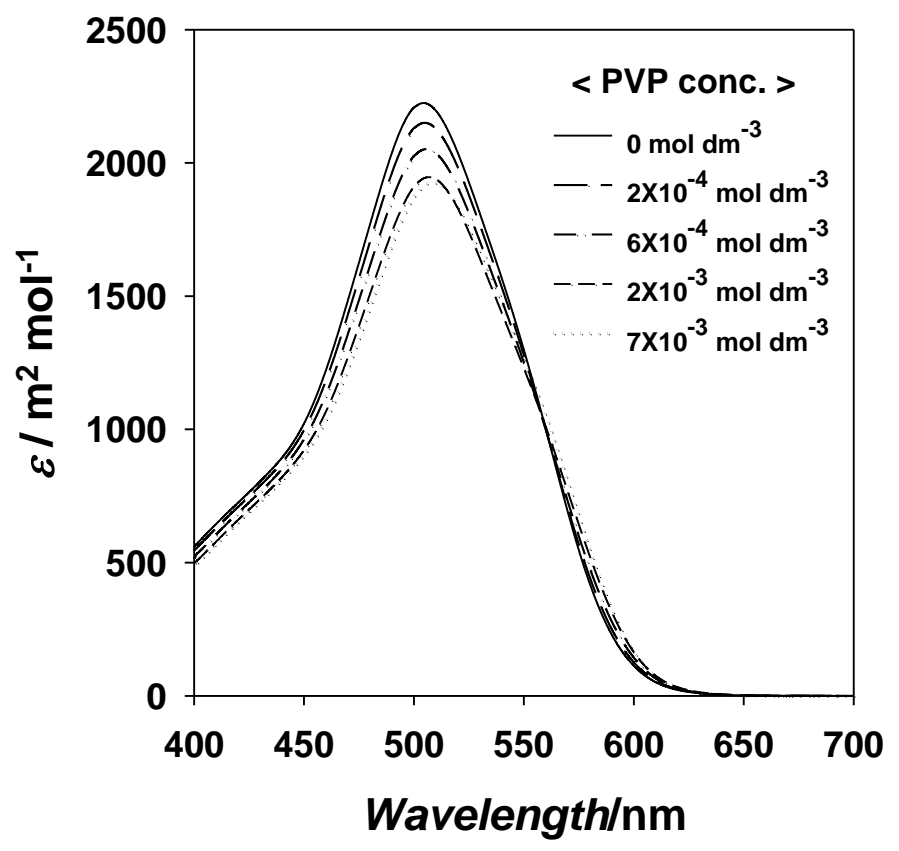

Figure 6 Visible absorption spectra of aqueous R-1 solutions in the absence and presence of PVP at $25{ }^{\circ} \mathrm{C}\left(\mathrm{R}-1\right.$ concentration: $\left.2.97 \times 10^{-5} \mathrm{~mol} \mathrm{dm}{ }^{-3}\right)$ 


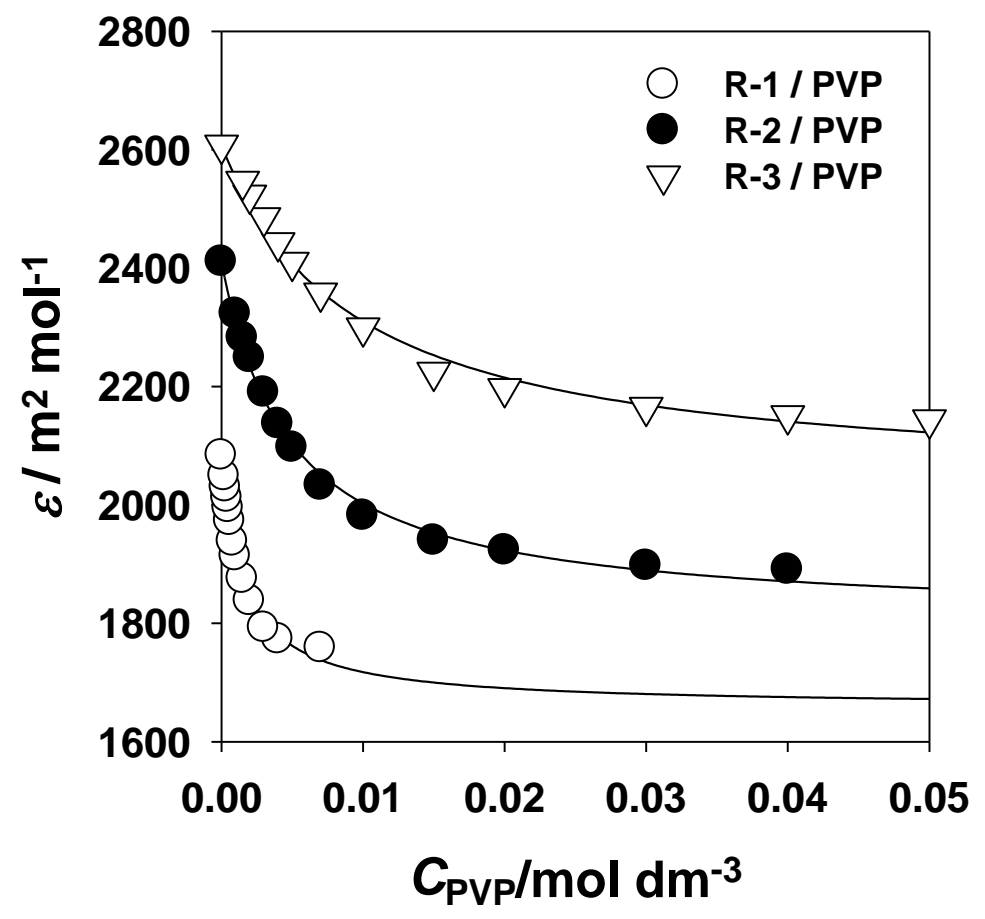

Figure 7 Dependence of $\varepsilon$ on PVP concentration at $25{ }^{\circ} \mathrm{C}$ (R-1, $492 \mathrm{~nm}$; R-2, $494 \mathrm{~nm}$; $\mathrm{R}-3,509 \mathrm{~nm})$ : The solid lines show the calculated extinction coefficients 


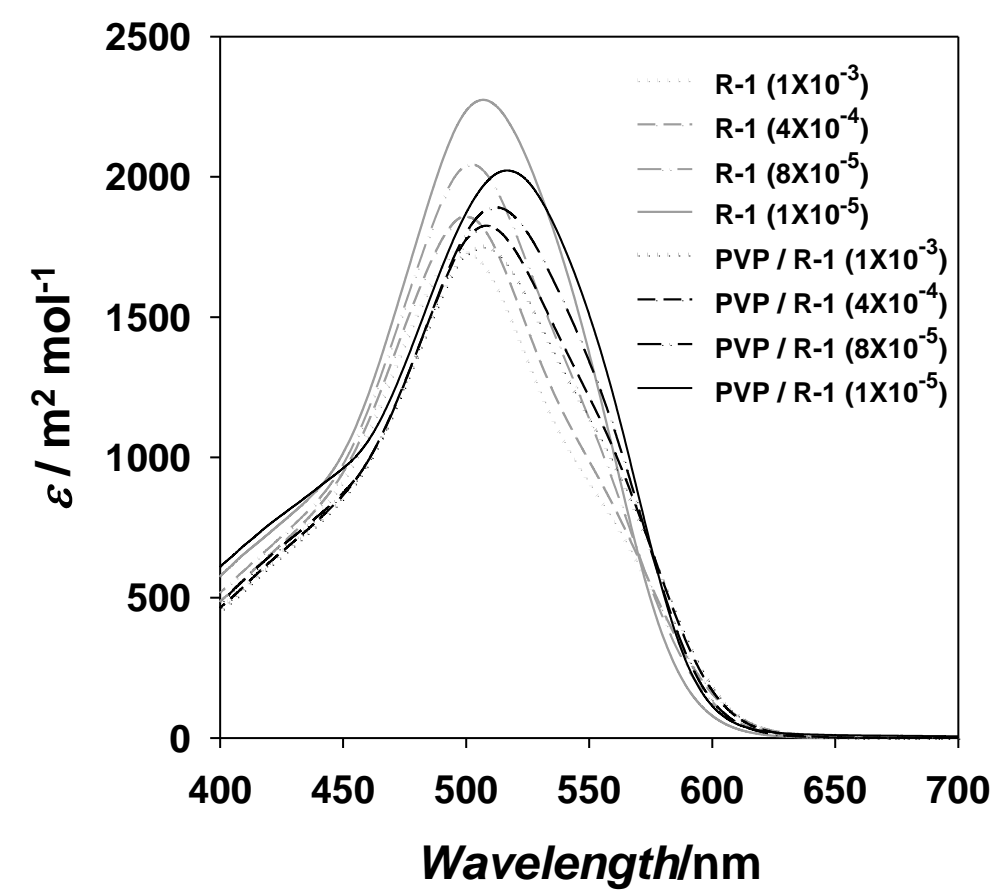

Figure 8 Visible absorption spectra of R-1 aqueous solutions in the absence and presence of PVP $\left(0.1 \mathrm{~mol} \mathrm{dm}^{-3}\right)$ at $25^{\circ} \mathrm{C}$ 


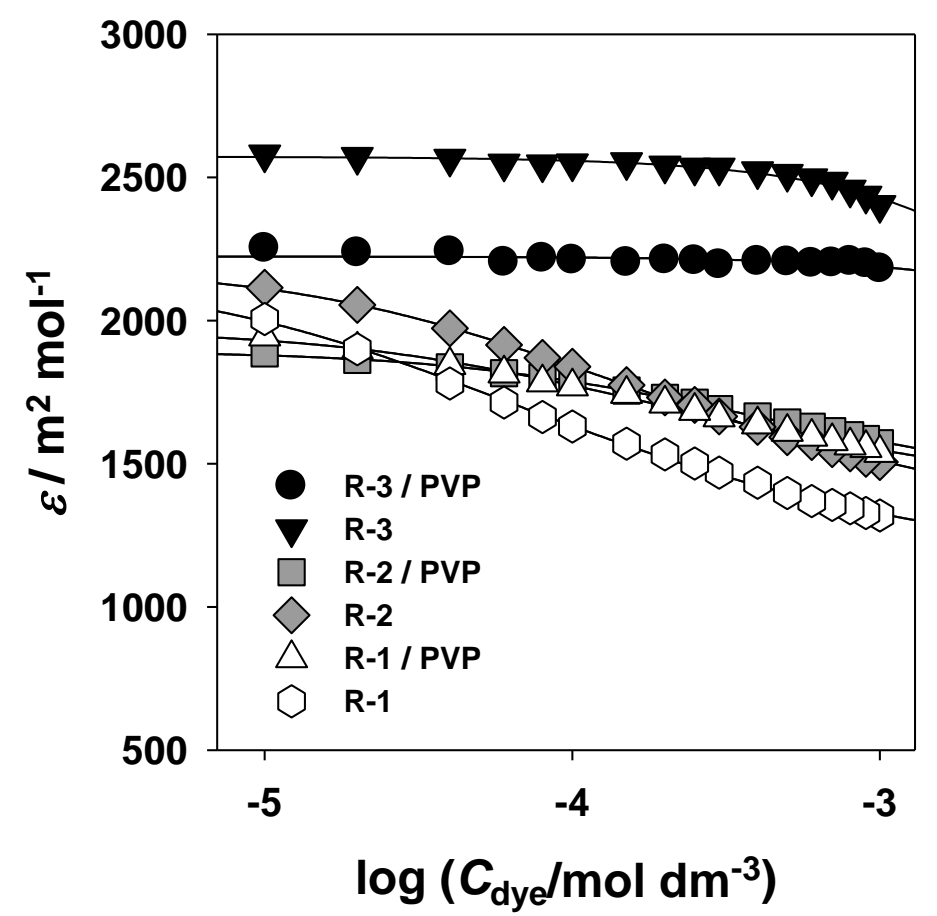

Figure 9 Dependence of $\varepsilon$ on the dye concentration in the absence and presence of PVP $\left(0.1 \mathrm{~mol} \mathrm{dm}^{-3}\right)$ at $25{ }^{\circ} \mathrm{C}$ and $526 \mathrm{~nm}$ : The solid lines show the calculated extinction coefficients 


\section{SEQUENCE OF TABLES THAT APPEARED IN THE MANUSCRIPT}

Table 1 The aggregation constants and thermodynamic parameters

Table 2 The $\varepsilon_{\mathrm{D}}$ and $\varepsilon_{\mathrm{D} 2}$ values $\left(\mathrm{m}^{2} \mathrm{~mol}^{-1}\right)$ at $526 \mathrm{~nm}$

Table 3 Binding constants and thermodynamic parameters for the binding of the dyes with PVP

Table 4 Aggregation constants and thermodynamic parameters in the presence of PVP

Table 5 The $\varepsilon_{\mathrm{bD}}$ and $\varepsilon_{\mathrm{bD} 2}$ values $\left(\mathrm{m}^{2} \mathrm{~mol}^{-1}\right)$ at $526 \mathrm{~nm}$ in the presence of PVP 
Table 1 The aggregation constants and thermodynamic parameters

\begin{tabular}{ccccccc}
\hline & \multicolumn{5}{c}{$\boldsymbol{K}_{\text {agg }}\left(\mathrm{dm}^{3} \mathrm{~mol}^{-1}\right)$} & \multirow{\Delta}{\Delta}{$\boldsymbol{H}_{\text {agg }}$} \\
\cline { 2 - 6 } & $\mathbf{1 5}^{\circ} \mathbf{C}$ & $\mathbf{2 5}^{\circ} \mathbf{C}$ & $\mathbf{3 5}^{\circ} \mathbf{C}$ & $\mathbf{4 5}^{\circ} \mathbf{C}$ & $\begin{array}{c}\Delta \boldsymbol{S}_{\text {agg }} \\
\left(\mathrm{J} \mathrm{mol}^{-1} \mathrm{~K}^{-1}\right)\end{array}$ \\
\hline $\mathbf{R}-1$ & $15900 \pm 1900$ & $10200 \pm 900$ & $7100 \pm 500$ & $4600 \pm 300$ & $-31.1 \pm 1.1$ & $-28 \pm 4$ \\
& $(21400 \pm 300)$ & $(14700 \pm 200)$ & $(9100 \pm 200)$ & $(5810 \pm 120)$ & $(-33.4 \pm 1.7)$ & $(-33 \pm 6)$ \\
& & & & & & $-76 \pm 8$ \\
$\mathbf{R - 2}$ & $7500 \pm 300$ & $4600 \pm 200$ & $2500 \pm 100$ & $1370 \pm 80$ & $-43 \pm 2$ & $-76 \pm 0$ \\
& $(8360 \pm 150)$ & $(5100 \pm 80)$ & $(2840 \pm 60)$ & $(1390 \pm 40)$ & $(-45 \pm 4)$ & $(-82 \pm 11)$ \\
$\mathbf{R - 3}$ & $3 \pm 7$ & $3 \pm 15$ & $0 \pm 60$ & $0 \pm 60$ & & \\
\hline
\end{tabular}

* ( ) shows values determined in Ref. 31 
Table 2 The $\varepsilon_{\mathrm{D}}$ and $\varepsilon_{\mathrm{D} 2}$ values $\left(\mathrm{m}^{2} \mathrm{~mol}^{-1}\right)$ at $526 \mathrm{~nm}$

\begin{tabular}{ccccc}
\hline & $\mathbf{1 5}^{\circ} \mathbf{C}$ & $\mathbf{2 5}^{\circ} \mathbf{C}$ & $\mathbf{3 5}^{\circ} \mathbf{C}$ & $\mathbf{4 5}^{\circ} \mathbf{C}$ \\
\hline $\boldsymbol{\varepsilon}_{\mathbf{D}}$ & 2136 & 2148 & 2159 & 2134 \\
$\mathbf{R}-\mathbf{1}$ & 2181 & 2184 & 2154 & 2118 \\
$\mathbf{R}-2$ & 2690 & 2648 & 2602 & 2557 \\
$\mathbf{R}-3$ & 1123 & 1122 & & \\
$\boldsymbol{\varepsilon}_{\mathbf{D} 2}$ & 1236 & 1249 & 1143 & 1154 \\
$\mathbf{R}-\mathbf{1}$ & - & - & - & - \\
$\mathbf{R}-2$ & & & - & 1249 \\
$\mathbf{R}-3$ & & & - & \\
\hline
\end{tabular}


Table 3 Binding constants and thermodynamic parameters for the binding of the dyes with PVP

\begin{tabular}{ccccccc}
\hline & \multicolumn{5}{c}{$\boldsymbol{K}_{\text {bind }}\left(\mathrm{dm}^{3} \mathrm{~mol}^{-1}\right)$} & \multirow{\Delta}{\Delta}{$\boldsymbol{H}_{\text {bind }}$} \\
\cline { 2 - 5 } & $\mathbf{1 5}^{\circ} \mathbf{C}$ & $\mathbf{2 5}^{\circ} \mathbf{C}$ & $\mathbf{3 5}^{\circ} \mathbf{C}$ & $\mathbf{4 5}^{\circ} \mathbf{C}$ & & $\begin{array}{c}\Delta \boldsymbol{S}_{\text {bind }} \\
\left(\mathrm{J} \mathrm{mol}^{-1} \mathrm{~K}^{-1}\right)\end{array}$ \\
\hline $\mathbf{R}-1$ & $780 \pm 90$ & $630 \pm 60$ & $480 \pm 40$ & $380 \pm 30$ & $-18.4 \pm 0.7$ & $-8 \pm 2$ \\
$\mathbf{R - 2}$ & $266 \pm 19$ & $208 \pm 14$ & $165 \pm 11$ & $125 \pm 7$ & $-18.9 \pm 0.9$ & $-19 \pm 3$ \\
$\mathbf{R - 3}$ & $132 \pm 13$ & $110 \pm 10$ & $87 \pm 7$ & $70 \pm 5$ & $-16.0 \pm 0.5$ & $-15.0 \pm 1.5$ \\
\hline
\end{tabular}


Table 4 Aggregation constants and thermodynamic parameters in the presence of PVP

\begin{tabular}{|c|c|c|c|c|c|c|}
\hline & \multicolumn{4}{|c|}{$\boldsymbol{K}_{\mathrm{agg}}{ }^{\mathbf{P V P}}\left(\mathrm{dm}^{3} \mathrm{~mol}^{-1}\right)$} & \multirow{2}{*}{$\begin{array}{c}\Delta \boldsymbol{H}_{\mathrm{agg}} \mathbf{P V P} \\
\left(\mathrm{kJ} \mathrm{mol}^{-1}\right)\end{array}$} & \multirow{2}{*}{$\begin{array}{c}\Delta \boldsymbol{S}_{\mathrm{agg}}^{\mathbf{P V P}} \\
\left(\mathrm{J} \mathrm{mol}^{-1} \mathrm{~K}^{-1}\right)\end{array}$} \\
\hline & $15^{\circ} \mathrm{C}$ & $2^{\circ} \mathrm{C}$ & $35^{\circ} \mathrm{C}$ & $4^{\circ} \mathrm{C}$ & & \\
\hline R-1 & $4400 \pm 600$ & $3400 \pm 400$ & $2300 \pm 300$ & $1900 \pm 300$ & $-22.5 \pm 1.5$ & $-8 \pm 4$ \\
\hline R-2 & $2320 \pm 150$ & $1490 \pm 90$ & $1180 \pm 120$ & $890 \pm 90$ & $-24 \pm 2$ & $-18 \pm 7$ \\
\hline
\end{tabular}


Table 5 The $\varepsilon_{\mathrm{bD}}$ and $\varepsilon_{\mathrm{bD} 2}$ values $\left(\mathrm{m}^{2} \mathrm{~mol}^{-1}\right)$ at $526 \mathrm{~nm}$ in the presence of PVP

\begin{tabular}{ccccc}
\hline & $\mathbf{1 5}^{\circ} \mathbf{C}$ & $\mathbf{2 5}^{\circ} \mathbf{C}$ & $\mathbf{3 5}^{\circ} \mathbf{C}$ & $\mathbf{4 5}^{\circ} \mathbf{C}$ \\
\hline $\boldsymbol{\varepsilon}_{\text {bD }}$ & & & & \\
$\mathbf{R}-1$ & 1979 & 1967 & 1927 & 1911 \\
$\mathbf{R}-2$ & 1913 & 1894 & 1873 & 1838 \\
$\boldsymbol{\varepsilon}_{\mathbf{b D 2}}$ & & & & \\
$\mathbf{R}-1$ & 1360 & 1353 & 1336 & 1322 \\
$\mathbf{R}-2$ & 1360 & 1327 & 1324 & 1333 \\
\hline
\end{tabular}

